\title{
Enseñanza de la filosofía en una sociedad democrática
}

\author{
Simón Bolívar* \\ Universidad Pedagógica y Tecnológica de Colombia
}

Una pregunta cobra hoy actualidad: ¿la filosofía necesita de la pedagogía? Si la respuesta es afirmativa, como argumentamos aquí, cabe también preguntarse: ¿esta necesidad será acaso la condición misma para que la enseñanza de la filosofía conduzca a una sociedad más igualitaria, más libre, y por ende más democrática?

La idea de una filosofía autosuficiente es ociosa y adolece de realismo. La idea de unas pedagogías ajenas a toda raigambre disciplinar es peligrosa y anodina. ¿Por qué entonces elegir entre centrar la enseñanza sobre el saber o sobre el estudiante? El acto de enseñar debe referirse a ambos polos y centrarse en el modo y en el contenido. Esto sólo se puede lograr cuando el educador mismo se sabe y se siente estudiante.

Palabras clave: práctica pedagógica, democracia, enseñanza, filosofía, espíritu científico

\section{THE TEACHING OF THE PHILOSOPHY IN A DEMOCRATIC SOCIETY}

One question becomes current: does the philosophy need the pedagogy? If the answer is an affirmative one, like we here argue, one can also pose the question: would be this need perhaps itself the condition that makes possible, that the teaching of the philosophy leads to a more egalitarian society, more free and because of this more democratic?

The idea of a self-sufficient philosophy is pointless and lacks in realism. The idea of some pedagogyes without any disciplinary root is dangerous and insubstantial. Why then do we have to choose between focusing on the knowledge or on the student? The act of teaching must refer to both poles and must focus on the way and of the content. That can only be achieved when the educator knows and feels himself as a student.

Key words: pedagogical practice, democracy, teaching, philosophy, scientific spirit.

* Filósofo de la Universidad Nacional de Colombia. Director de la revista "Cuestiones de Filosofía". Docente Universidad Pedagógica y Tecnológica de Colombia. 


\section{Introducción}

$\mathrm{L}$ a relación entre filosofía y pedagogía es tan antigua que se encuentra en el origen mismo de la reflexión filosófica en la Grecia clásica, particularmente en las disputas mantenidas entre los sofistas y Platón, en el contexto del llamado siglo de Pericles, en el que Atenas conquistó para todos los ciudadanos, merced a su vocación pedagógica, tanto la isonomía como la isegoría, elocuente expresión de la entonces pujante democracia.

Dejando atrás esta historia, una pregunta cobra hoy actualidad: ¿la filosofía necesita de la pedagogía? Si la respuesta es positiva, como trataremos de demostrar, cabe también preguntarse: ¿esta necesidad será acaso la condición misma para que la enseñanza de la filosofía conduzca a una sociedad más igualitaria, más libre y, por ende, más democrática?

Los tiempos de la philosophia perennis, tan cara a la escolástica, en los que la inmutabilidad del pensamiento, ajeno a la historia, hacía anodina su enseñanza, cuando no patrimonio de elegidos, parecen hoy perimidos. Heredero tardío de la ilustración francesa, Gaston Bachelard sostuvo siempre tesis polémicas en contra de la eternidad e inmutabilidad del saber y del peligro que para el conocimiento podría significar la ignorancia de la historia y el desdén por la pedagogía, lo cual lo llevó a afirmar no sólo que "El conocimiento se dinamiza por el hecho mismo de su historicidad. Teniendo una historia, tiene un destino. Y esa historia es pedagógica." ${ }^{1}$, sino también que, dadas todas las revoluciones científicas y tecnológicas acaecidas durante la primera mitad del siglo XX, había llegado la hora de que la filosofía escuchara las lecciones de las ciencias, abandonando su sempiterno atributo de "madre de todas las ciencias".

\section{Filosofía y Pedagogía}

En principio, parece una claudicación reconocer que la filosofía tenga necesidad de la pedagogía y deba escuchar las lecciones y aprender de las ciencias. No obstante, hay que recordar que durante toda la Edad Media la filosofía no fue otra cosa que ancilla theologiae, y que su papel de sierva sólo concluyó con la secularización del conocimiento en los albores de la edad moderna.

Ahora bien, una tesis habitualmente admitida entre los profesores de filosofía quiere que la filosofía se baste a sí misma, que su enseñanza no dependa más que de la sola competencia disciplinaria, y que no tenga nada que ver con la pedagogía, a la que no es fácil reconocerle un estatuto científico. Por lo demás no es tampoco necesario que lo sea, pues las disputas sobre su carácter científico suelen conducir a la ideologización de lo pedagógico, esto es, al pedagogismo. La pedagogía misma puede conformarse con reconocerse a sí misma como una simple práctica, testimoniando con esta actitud en favor de sus propios orígenes históricos y etimológicos.

Una primera objeción contra la intrusión de la pedagogía en la clase de filosofía 
considera que la preocupación por el estudiante se haría siempre en detrimento del saber, pues se tiene siempre la idea de que la pedagogía no es más que una ciencia (cuando se la reconoce como tal) de la enseñanza en general, que no tiene en cuenta para nada la materia a enseñar. El mismo Bachelard señalaba a este respecto que le sorprendía mucho que los profesores no entendieran las razones por las cuales el estudiante no entiende, pues a menudo creen que el conocimiento comienza con una simple lección, olvidando que el estudiante llega a la clase no en tanto que tabula rasa sino provisto de un tejido de errores y prejuicios tenaces que hay que comenzar por deshacer. Para pensar, en efecto, en primer lugar hay que desaprender, es decir, reconocer que no hay "verdades primeras" sino únicamente "errores primeros".

Ahora bien, si filosofía y pedagogía fueran mutuamente excluyentes, una enseñanza filosófica de calidad impondría con toda seguridad ignorar la reflexión sobre las condiciones mismas de construcción del saber, proceso que ha tenido siempre sus fracasos, derrotas, dudas y vacilaciones. Además, la cuestión central está en saber si el hecho de despertar en el estudiante inquietudes sobre su propia realidad psicológica y social es necesariamente incompatible con una real exigencia filosófica.

Otra objeción tiene que ver con la pretensión de justificar la exclusión de la pedagogía fuera de la clase de filosofía y, más aún, fuera de la institución educativa misma, debido a que aquélla lo que hace es interesarse en el estudiante bajo todas sus dimensiones, intentando comprender las relaciones entre su vida afectiva, familiar y social con respecto a su aprendizaje. En otras palabras, no podría haber relación alguna entre el llamado mundo real social y la institución educativa.

Por la fuerza de las circunstancias, la acción pedagógica abriría las puertas de la institución educativa a los ruidos del exterior, enfatizando que la inscripción social y psicológica de un estudiante en su medio no es indiferente a su devenir escolar. Lejos de legitimar la pretendida homogeneidad que la institución educativa postula, la pedagogía, o mejor, las pedagogías, al diferenciarse, es decir, al abandonar las pretensiones de universalidad y generalidad, podrían acometer el trabajo concreto de trabajar con estudiantes concretos. Es en este sentido en el que Bachelard, hacia 1940, había planteado la necesidad de una filosofía diferencial que pudiera dar cuenta del estadio de objetividad en que hubiera de encontrarse cada ciencia en particular, con el fin de restituir su propia historia desde su actualidad: "Cada hipótesis, cada problema y experiencia, cada ecuación, reclamarían su filosofía. Debería fundarse una filosofía científica diferencial (...) Esta filosofía diferencial tendría a su cargo medir el devenir de un pensamiento (...) Meditando filosóficamente sobre cada noción, veríamos también con mayor claridad el carácter polémico de la definición empleada, todo lo que esa definición distingue, suprime, niega" ${ }^{2}$.

Pero es, sin duda, Philippe Meirieu quien más ha desarrollado esta idea en su dimensión pedagógica, cuando señala: “La pedagogía diferenciada, sobre todo, antes que ser un conjunto de métodos y técnicas de organización del trabajo escolar, es la expresión de la voluntad de hacer con. Hacer con el alumno concreto, tal como lo encontramos, fruto de una historia intelectual, psicológica y social, una historia que 
no puede abolirse por decreto" ${ }^{3}$. El "alumno concreto" es el proveniente de un medio socioeconómico deprimido u opulento, es también el tímido y el intrépido, el hábil para la abstracción o el sensible al arte, en fin, es también el que se encuentra a medio camino entre estas parejas de extremos.

He ahí lo incómodo y escandaloso que resulta esto último para quienes quieren hacer de la institución educativa un "templo del saber", donde serían abolidas precisamente todas las diferencias. Tal abolición no se haría en el sentido de "democratizar", suprimiendo privilegios sino en el sentido de "homogeneizar", suprimiendo discrepancias y poniendo un velo sobre la realidad, en busca de un único modo de pensar, de sentir y de actuar: "En otras palabras, me parece que la democracia no puede construirse dentro de una relación pedagógica en la cual el educador se conforme con exhortar a los alumnos o con afirmar que el acceso al saber es inmediato y conduce naturalmente hacia una inteligencia racional libre de cualquier envoltorio afectivo y social" ${ }^{4}$.

Si la institución educativa fuera un templo, la clase de filosofía sería el púlpito o el altar donde se predicaría la palabra revelada, y el filósofo devendría "el sacerdote enmascarado" que nos ha dibujado Nietzsche en La Genealogía de la Moral.

De igual forma, la tesis que quiere que la institución educativa sea un templo considera que aquélla es ese lugar al margen de los apremios cotidianos y de las condiciones particulares de la existencia, una suerte de burbuja de cristal ajena al histórico discurrir de la vida. Ordenada en todo sentido a lo universal, la institución educativa quiere ser la otra cara de la vida real y de sus reflejos ideológicos. Si quitamos esos apremios particulares que afligen a esas vidas particulares nos queda como residuo común a todos los hombres lo universal, es decir, lo otro de la vida real.

La institución educativa sería ese lugar ajeno a la historia donde el hombre aprendería a mantener una relación directa con lo universal y con tareas obligatorias, cuando no tediosas, que lo sustraerían a sus propias condiciones particulares de existencia. Un lugar en donde todo quedaría vigilado por una razón omnipresente. Sin embargo: “...son muchas las formas del discurso totalitario que intenta asegurar su poder prohibiendo el examen crítico; y son tantas y tan poderosas y sugerentes que es necesario que todas las actividades pedagógicas contribuyan a detectarlas" 5 .

\section{Sujetos abstractos y sujetos reales}

De una u otra manera los ingredientes de la argumentación son siempre los mismos: ignorar la vida real y definir la institución educativa como espacio de excepción, ahistórico, fuera de la sociedad civil. Dicho de otra manera, la institución educativa, al suprimir las diferencias reales de los estudiantes, estaría ante un sujeto abstracto proclive naturalmente hacia el conocimiento.

El estudiante que se dirige al profesor no sería ya ni Juan ni Pedro sino un espíritu disponible, esto es, liberado de sus ataduras culturales, en suma, un puro sujeto 
cognoscente. Sin embargo, es evidente que ni siquiera el hombre mismo de ciencia es racionalidad pura, sino que en él persisten, como en cualquier otro sujeto, zonas oscuras donde habitan sus emociones, sus miedos, su cultura misma, tal como nos lo recuerda Popper: "Pero el hombre es, asimismo, algo más que un animal racional, puesto que todo lo que importa realmente en su vida va más allá de los límites de la razón. Aun los pocos hombres de ciencia que toman en serio la razón y la ciencia están comprometidos en su actitud racionalista solamente porque la aman. De este modo, aún en esos raros casos, es la configuración emocional del hombre y no su razón la que determina la actitud final" ${ }^{6}$.

Si es vano, desde este punto de vista, ignorar las condiciones reales del estudiante, es porque este no puede ser percibido sino como un ignorante al que conviene instruir, o un espíritu cognoscente puro abierto naturalmente y espontáneamente al conocimiento. En tanto la institución educativa tenga predominantemente una vocación universal no considerará sino sujetos abstractos, sujetos epistémicos. Su pretendida universalidad riñe con la historia, es atemporal. En ningún caso sujetos reales, sujetos de carne y hueso. El prejuicio ante lo social y el desdén por la realidad se pasean ufanos por todos los ámbitos de la institución educativa.

Se puede ver ahora cómo la enseñanza filosófica ha sido tradicionalmente pensada como incompatible con la toma en consideración de las determinaciones particulares que hacen que Juan no aprenda tanto como Pedro. Comprometerse en el sendero de las pedagogías sería admitir que el estudiante es un sujeto empírico inscrito en un contexto y en una historia, y que cuando entra en la educación nunca se despoja de lo que hace de él un sujeto singular, a menos que la educación misma se encargue de ese despojo.

Tal despojo, hecho en nombre de lo universal no pretende otra cosa que suprimir las diferencias culturales, las raíces mismas que hacen que una persona sea lo que es, es decir, su dignidad. Suprimiendo dichas raíces se suprime la historia misma de la persona, y el conocimiento se torna algo ajeno, algo extraño que no orienta, que no abre un mundo, un producto artificial e innecesario y nada más. La inteligencia cede su puesto a la memorización, la crítica a la escolástica. Se estudia para memorizar; se memoriza para no perder una evaluación.

Es del estudiante real, con sus determinaciones específicas, de quien a menudo no quieren saber nada los filósofos, acostumbrados como suelen estar a tratar con abstractos sujetos epistémicos. El acceso al "yo" pasa, a sus ojos, por una renuncia al "nosotros", es decir, a todo aquello en donde el individuo real vive y padece. Los filósofos no han escuchado la conminación bachelardiana acerca de que la ciencia y la filosofía hace rato que dejaron de ser el cogito de un yo solitario y aislado para devenir hoy en día un laborioso y difícil cogitamus.

La pregunta inicial: ¿tiene la filosofía necesidad de la pedagogía?, cobra aquí un nuevo sentido: ¿a quién nos dirigimos cuando hacemos clase? ¿Qué pretendemos con el discurso racional que desplegamos? ¿Es legítimo considerar al estudiante como un 
ignorante, esto es, como un sujeto a instruir? ¿Se puede ignorar las diferencias individuales? ¿Podemos suponer un sujeto universal preexistente a todas las diferencias? ¿No será que ese sujeto residual, huésped de la institución educativa en tanto que templo del saber y lo otro de la vida real no es más que un ser abstracto, un fantasma? ¿Y, en este mismo orden de ideas, tratar con fantasmas no es esquizoide? Estas son las preguntas que hay que afrontar.

\section{Pedagogías de la diferencia y devenir de la democracia}

Tanto la verdad como el sujeto mismo suelen ser procesos que necesitan de una dinamización y recreación permanente, en un contexto social e histórico concreto, pues no pueden existir a priori: "Una verdad no alcanza su pleno sentido sino al término de una polémica. No puede haber verdad primera. Sólo hay errores primeros. No debe vacilarse, pues, en anotar en el activo del sujeto su experiencia esencialmente infortunada. La primera y más esencial función de la actividad del sujeto es engañarse. Cuanto más complejo sea su error, más rica será su experiencia. La experiencia es, precisamente, el recuerdo de los errores rectificados" 7 .

Partir de lo que el otro sabe es aquí tan importante como reconocer sus errores y los propios, además de admitir que la verdad se construye paulatinamente. Luego ni hay tabula rasa de la cual partir ni el saber es construido por espíritus desencarnados: “...los saberes son construidos por personas vivas en un determinado momento de su historia; personas que no se reducen a un segmento lógico-racional idéntico en todas, personas con las que no basta la clonación para educarlas" 8 .

El maestro debe ser, pues, no simplemente un pedagogo sino también alguien cuyo fuerte compromiso con su labor y con el conocimiento es puesto permanentemente en evidencia: "Una suerte de reacción de la claridad pedagógica del maestro se manifiesta en la puesta en orden del espíritu del discípulo enseñado. Es necesaria una fuerte personalidad para enseñar lo impersonal, para transmitir los intereses del pensamiento independiente de los intereses personales" 9 .

La necesidad de una pedagogía diferencial o diferenciada se impone, pues es necesario que el espíritu se halle siempre en estado de pedagogía permanente por el hecho mismo del devenir del conocimiento, por el hecho de que su actualidad hace que se esté permanentemente revisando y rehaciendo su pasado: "Pero el espíritu no se instituye con toda facilidad como una consciencia del rigor de la demostración. Tendremos que insistir sobre la necesidad de restituir la consciencia de lo no-riguroso para que sea posible una plena toma de consciencia del rigor. De este modo las instancias pedagógicas se revelarán eficaces, indispensables. Nos mostrarán que la ciencia es escuela, una escuela permanente." ${ }^{10}$. El espíritu al que alude Bachelard no es una simple abstracción sino la expresión misma de la dialéctica maestro-discípulo, que él denomina también dialéctica del racionalismo enseñante y del racionalismo enseñado, en la que una consciencia de lo no-riguroso superado por un afinamiento paulatino del rigor equivale a la libertad misma de pensar, pues sólo se puede ser libre de pensar y de construir conocimiento cuando se triunfa sobre un pasado de errores. 
Meirieu, por su parte, parece estar comentando a Bachelard cuando señala: “El docente conoce muy bien esta vieja cuestión filosófica que las resistencias de los alumnos a la racionalidad reactivan día a día, resistencias organizadas o en incubación, resistencias de los prejuicios y de los intereses, resistencias de las pasiones o de las inhibiciones, resistencias de todo tipo que a veces nos hacen exclamar: ${ }_{i}$ No entiendo que no entendáis!"11. Es porque el maestro, parafraseando a Bachelard, ignora que hay obstáculos epistemológicos, tan arraigados en el acto mismo de conocer, que sólo después de complicadas catarsis se pueden superar.

De otro lado, si hay una objeción que hacerle a la pedagogía no es la de reducir la dimensión disciplinaria, sino el hecho de olvidar sus orígenes y creer inventar allí donde no está haciendo otra cosa que regresar a los orígenes. No pocas veces la pedagogía deviene vana metodología. Pero su legitimidad no parece poder ser puesta en duda: un profesor de filosofía necesita, como cualquier otro, de un mínimo de información sobre la manera de enseñar. Urge siempre la posibilidad de cambiar de métodos o de estrategias: "A lo largo de una ya larga y diversa carrera, jamás he visto a un educador cambiar de método de educación. El educador no tiene el sentido del fracaso precisamente porque se cree un maestro" ${ }^{12}$.

Esta aseveración no es más que una entre decenas que ilustrarían la falta de realismo que hay cuando se niega la diversidad concreta en nombre de una supuesta universalidad epistémica. Y es aquí donde cabe señalar la importancia que hay tanto en la manera de enseñar como en la materia enseñada.

Ahora bien, cuando la pedagogía deviene un discurso estrictamente técnico, corre el riesgo de olvidar el camino hacia la búsqueda del saber. Dicho de otro modo, la forma deviene su única preocupación cuando la cuestión de los contenidos se ha relegado como vana. Es aquí donde la pedagogía necesita de la filosofía, ya que forma y materia deben estar estrechamente unidas. La filosofía debe velar aquí para mantener viva la cuestión del sentido y de la finalidad. El riesgo se da cuando el profesor deviene moralista y utiliza el saber con fines manipuladores: "La verdadera satisfacción del educador sería que aquél a quien ha educado le saludase como hombre libre y lo reconociera como su educador sin ser, con ello, su vasallo"13.

La búsqueda de un simple coro entre los educandos no es otra cosa que el supremo fin de los profesores manipuladores, quienes en nombre de un saber no pocas veces precario e inconsistente, ejercen un talante autoritario caracterizado, en sus actitudes, por una relación de amonestación, así como por la utilización de amenazas y reclamos permanentes hacia aquéllos.

No hay duda de que la pedagogía ofrece un arsenal de medios de análisis del fracaso escolar y de su superación. Negar la universalidad abstracta y tener en cuenta el contexto de la actividad enseñante no significa automáticamente caer en el escepticismo o en la sofística. Hay grandes riesgos en hacer la apología de la diferencia por la diferencia. Por lo tanto, hay que tratar de ir hacia un equilibrio entre la búsqueda de un saber universal y su inserción en la historia en donde lo universal no sea lo dado $a$ 
priori sino una pretensión a la que sólo se llegaría por medio de la discusión entre interlocutores animados por convicciones diferentes pero que admitirían que hay tantos universales como culturas y formas de vida, expresados en un abierto y horizontal diálogo permanente, esto es, en un cogitamus.

Tales consideraciones no parecen tener nada que ver con la enseñanza, pero Philippe Meirieu ha sabido darles una dimensión pedagógica cuando exige que los estudiantes sean tenidos en cuenta como "seres-en-situación". No basta, señala él, con despojarlos de toda adhesión a sus situaciones concretas y encarnadas para volverlos disponibles al estudio y a lo universal. Tales situaciones son constitutivas de la persona del estudiante y son precisamente las que las pedagogías de la diferencia pueden ayudar a conocer para ir al reencuentro del otro allí donde él está: "En realidad, la fascinación por lo universal demuestra una ignorancia de los seres-en situación. Se enfrenta así a ellos de lleno y sólo puede constatar que son refractarios a su propósito, lo cual, en el peor de los casos, arma el brazo que retomará las riendas de modo autoritario" ${ }^{14}$.

\section{A modo de conclusión}

Dos dificultades parecen imponerse: a fuerza de centrarse en el saber se acaba por ignorar o menospreciar al destinatario de dicho saber. Esta es una tendencia dogmática que postula un sujeto universal, por lo tanto racional, y de entrada accesible a la enseñanza.

A fuerza de enfocarse en el conocimiento del estudiante en detrimento de los conocimientos que se le quieren enseñar a construir, se corre el riesgo de olvidar las razones por las cuales surgió el interés por dicha persona y por el conocimiento mismo.

Cada una de estas tendencias tiene razón en la medida en que la otra no y viceversa. O mejor: sus denuncias están plenamente justificadas, en tanto que sus pretensiones están sujetas al porvenir de la institución educativa. Es razonable preocuparse por los contenidos de la enseñanza, pero no hay que caer en el pedagogismo, esto es, en la pura reducción ideológica de lo más preciado de la pedagogía, que consiste en interesarse por el estudiante. Preocuparse por el estudiante tiene sentido sólo si se mantienen las exigencias disciplinarias, y si al lado de estas se busca formar seres libres y con vocación democrática: "Un ideal político que tenga como finalidad la promoción de todos los hombres al rango de sujetos, un proyecto que lleve en sí la perspectiva de la universalidad, sólo puede llegar a un buen fin si se toma el tiempo de trabajar a partir de lo pedagógico, de lo concreto, de lo particular, de lo histórico, si se toma la molestia de partir de situaciones en las cuales las personas están implicadas, en lugar de exhortarlas, sin ninguna posibilidad de éxito, a pensar y a actuar sólo como abstracciones" ${ }^{15}$.

Dicho de otra manera, las llamadas pedagogías de la diferencia tienen tanta necesidad de la filosofía como ésta de aquéllas. La idea de una filosofía autosuficiente es ociosa y adolece de realismo. La idea de unas pedagogías ajenas a toda raigambre disciplinar es tan peligrosa como anodina. 
¿Por qué entonces elegir entre centrar la enseñanza sobre el saber o sobre el estudiante? El acto de enseñar debe referirse a ambos polos y preocuparse tanto por la forma como por el contenido. Esto sólo se puede lograr cuando el educador mismo se sabe y se siente estudiante: "El hombre consagrado a la cultura científica es un eterno escolar. La escuela es el modelo más elevado de la vida social. Seguir siendo un escolar debe ser la ambición secreta del maestro" ${ }^{16}$.

En aras de una educación que estimule el diálogo entre educador y estudiante, y que fortalezca la construcción de espacios democráticos en la escuela, y que por ende facilite la crítica y la discrepancia, quisiera terminar con una reflexión de Meirieu, quien es enfático al afirmar: "Por ello la exigencia educativa recusa a la vez el universalismo dogmático y el relativismo pragmático. Rechaza lo primero, por que al plantear la existencia de lo universal como una realidad exterior a las personas, $a$ priori, según la cual convendría medir las intenciones y las acciones humanas, genera todas las formas de colonialismo. Rechaza lo segundo porque, al negar la posibilidad de un horizonte universal en el que las personas puedan reconciliarse, ratifica la ley de la jungla y permite que venza la violencia del más fuerte. La exigencia educativa es la de un universalismo modesto, por la adhesión progresiva y difícil del otro a principios, valores y saberes que induce a revisar, ayuda a repensar por su propia resistencia, y que sólo él, sea como sea, tiene el poder de aceptar o rechazar" ${ }^{17}$.

\section{Notas}

1. Bachelard (2004), p. 103

2. Bachelard (1973a), p. 15

3. Meirieu (1998), pp. 109-110

4. Meirieu (2001), p. 172

5. Meirieu (2001), p. 174

6. Popper (1992), p.110

7. Bachelard (2004), p.101

8. Meirieu (1998), p. 110

9. Bachelard (1978), pp. 19-20

10. Bachelard (1978), p. 34

11. Meirieu (2001), p. 169

12. Bachelard (1986), p. 19

13. Meirieu (1998), p. 47

14. Meirieu (2001), p. 170

15. Meirieu (2001), p. 171

16. Bachelard (1978), p. 29

17. Meirieu (2001), pp. 86-87 


\section{Bibliografía}

Bachelard, Gaston (1973). El Compromiso Racionalista. Traducción de Hugo Beccacece. Buenos Aires: Siglo XXI Editores.

Bachelard, Gaston (1973a). La Filosofía del No. Buenos Aires: Amorrortu editores

Bachelard, Gaston (1951). L'activité Racionaliste de la Physique Contemporaine. Paris: PUF.

Bachelard, Gaston (1978). El Racionalismo Aplicado. Buenos Aires: Paidós.

Bachelard, Gaston (1986). La Formation de l'Esprit Scientifique: contribution à une psychanalyse de la connaissance objective. Paris: Vrin.

Bachelard, Gaston (2004). Estudios. Buenos Aires: Amorrortu Editores.

Guzman, María D. y otros (2000). La Escuela del siglo XXI y otras revoluciones pendientes. ¿Una pedagogía de lo imposible? Huelva: Hergué editorial.

Meirieu, Philippe (1997). La Escuela: modo de empleo. De los "métodos activos" a la pedagogía diferenciada. Barcelona: Ediciones Octaedro.

Meirieu, Philippe (1998). Frankenstein Educador. Barcelona: Alertes.

Meirieu, Philippe (2001). La Opción de educar. Ética y Pedagogía. Barcelona: Ocatedro

Platon (1924). Oeuvres completes, t. III, 2e partie. Paris: Les belles lettres.

Platon (1961). Oeuvres completes, t IV, 3e partie. Paris: Les belles lettres.

Platón (1983). Diálogos, v. II. Madrid: Editorial Gredos.

Platón (1986). Diálogos, v. IV. Madrid: Editorial Gredos

Popper, Karl R. (1992). La sociedad abierta y sus enemigos, v. II. Barcelona: Planeta-Agostini 